\title{
PANORAMAS, CONTEXTOS, GESTÃo E PRÁTICAS EM ACERVOS E COLEÇÕES
}

\author{
SCENARIOS, CONTEXTS, MANAGEMENT AND PRACTICES IN COLLECTIONS
}

\author{
Gustavo Souza Marques \\ gusmaocontato@gmail.com \\ Renata Lopes Leite \\ Mestranda do PPGCI- UFMG \\ renatalleite1@gmail.com \\ Tadeus Mucelli \\ Doutorando do PPGCI- UFMG \\ tadeus.mucelli@gmail.com \\ Samuel Ayobami Akinruli \\ Doutorando do PPGCI- UFMG \\ ayobami@insod.org
}

Doutorando em Música - University College Cork (UCC)

Recebido em: 24-04-2019

Aceito em: 03-07-2019

\begin{abstract}
Resumo: Este artigo surgiu na busca de referências bibliográficas consolidadas e ao mesmo tempo o encontro de uma diversidade considerável de temáticas relativas a gestão de acervos e coleções. Buscando compreender a gestão dos espaços de memória, refletindo sobre os termos acervos e coleções analisando seus sentidos atribuídos a partir de várias áreas em que se pratica ações envolvendo a temática. Contextualizando a gestão de coleções e suas práticas, pontuando a interdisciplinaridade e transversalidade das áreas envolvidas, apresentamos alguns exemplos.
\end{abstract}

Palavras-chave: Coleções de Museus. Coleções de Bibliotecas. Gestão de Acervos.

\begin{abstract}
This article emerged in the search for consolidated bibliographical references and at the same time the meeting of a considerable diversity of themes related to Collections Management. Seeking to understand the management of memory spaces, reflecting on the terms and collections analyzing their meanings attributed from various areas in which actions involving the theme are practiced. Contextualizing the management of collections and their practices, punctuating the interdisciplinarity and transversality of the areas involved, we present some examples.
\end{abstract}

Keywords: Museum Collections. Library Collections, Collections Management.

\section{PANORAMA}

A dificuldade na busca de referências bibliográficas consolidadas e ao mesmo tempo o encontro de uma diversidade considerável de temáticas relativas à gestão de acervos e coleções coloca em questão um contexto de atualidade no campo. Afinal, oque é possível dizer das práticas e teorias da gestão de acervos e coleções? Existem estudos e normas que fundamentam a gestão de coleções?

A condição digital como processo irreversível de um mundo em vias de digitalização de grande parte das ações, que compõe a vida de pessoas e instituições, torna mais complexa e diversificada as condições de 
inúmeras atividades. A gestão de coleções e acervos requer uma atenção não especificamente a normas difundidas que procuram estabilizar os documentos e arquivos, mas chama a nossa atenção, principalmente para uma processo anterior das ações de ordem prática, como as políticas de gestão e a conceitualização sobre como definir documentos, coleções, arquivos e acervos conforme as múltiplas possibilidades e conforme cada ator e instituição.

A fim de compreender a gestão dos espaços de memória, inquire-se sobre os termos acervos e coleções analisando seus sentidos atribuídos a partir de várias áreas em que se praticam ações envolvendo a temática. Tais conceitos podem ser definidos como conjuntos de objetos ou itens adquiridos, junto com informações coligidas a respeito, cuja guarda é mantida pela organização colecionadora ou, ainda, os itens mantidos por um colecionador. Na terminologia dos arquivos do Reino Unido, por exemplo, o termo "colecionador" é comumente usado como sinônimo de "aficionado". Dessa forma, além dos itens preservados dentro de um edifício, um acervo pode incluir o próprio edifício ou o local onde se encontra (RESOURCE, 2002).

Segundo Réau (1908), uma instituição como o museu nasce para as coleções e é necessário que as instituições sejam estabelecidas a partir dos seus conteúdos, de dentro para fora. Por outro lado, as práticas permitem que existam instituições com vários modelos incluindo aquelas que não possuem coleções físicas (REAU 1908).

Pela tradição da Ciência da Informação no Brasil, a gestão de acervos se dá entre as instituições públicas e/ou instituições privadas como os museus, bibliotecas e arquivos, de modo que as práticas de cada área provocam novos modos de fazer e, consequentemente, novas teorias. Assim, podemos deduzir que as novas definições dos campos da museologia, da biblioteconomia e da arquivologia emergem a partir da quebra de paradigmas em cada uma dessas áreas para contemplar novas variáveis que até então eram menos importantes para suas práticas. Portanto, tipicamente teremos acervos museológicos, bibliográficos, arquivísticos, além dos acervos e coleções híbridas ou contemporâneas que envolvem as interseções entre as ações das três áreas principais da Ciência da Informação. Passam a fazer parte da esfera de interesses tipos de acervos e coleções associados ao patrimônio cultural, sendo de duas grandes categorias - o material e o imaterial (BURCAW, 1997).

Assim, os acervos e coleções híbridos ou contemporâneos, de natureza material ou imaterial, incluem acervos arquitetônicos, monumentais e paisagísticos que envolvem características e conjuntos toponímicos e geográficos de determinado território. Incluem, pois, aspectos biológicos, computacionais, relacionados aos hardwares ou softwares, linguagens sonoras, questões linguísticas, itens artísticos, em ambiente digital ou virtual. Incorporam, ainda, processos científicos e tecnológicos como a propriedade intelectual. Vale ressaltar que todos os tipos de acervos precisam de uma espécie de dispositivos, bancos de dados, ambientes de armazenamento e recuperação de informação.

\section{CONTEXTOS}

Patrimonium, do latim, refere-se à propriedade herdada do pai ou dos antepassados. Os ingleses 
utilizam heritage, àquilo que foi ou pode ser herdado. No processo de generalização, passou a ser usado como referência aos monumentos herdados das gerações anteriores.

O conceito moderno de patrimônio, entretanto, foi criado apenas no século XVIII em decorrência da revolução Francesa e da necessidade de se criar símbolos nacionais e novos hábitos que pudessem construir o próprio cidadão (FUNARI; PELLEGRINI, 2006). Espalhou-se assim, por toda a Europa e mais tarde para as Américas, a constituição das memórias nacionais, a partir da escolha de determinados símbolos. Esta construção confere o caráter político da memória, da cultura e do patrimônio como artefatos socialmente construídos, portadores de significados, embora nas últimas décadas, as instituições portadoras de memória enfrentem tensões e contradições em decorrência dos estudos historiográficos contemporâneos em face às representações do passado expostas. A noção de patrimônio, há algumas décadas, se apoiava nos acontecimentos históricos e nas artes, hoje expandiu-se e se institui nos conceitos de cultura e memória, vinculando-se, geralmente, à Convenção sobre Proteção e Promoção da Diversidade Cultural (2005) da UNESCO.

O reconhecimento da diversidade cultural e a relação com identidades de grupos trouxe novas abordagens sobre o conceito e as funções do patrimônio na sociedade. O campo do patrimônio abrange atualmente muito mais do que coleções de objetos recolhidos nas viagens à terras distantes ou em algum cenário de guerra, envolve patrimônio científico, tecnológico, biológico, musical, literário, arquitetônico, documental, industrial e muitos outros, todos envolvendo informações decorrentes da atividade humana. Aballí (2009), no livro Ciência da Informação: múltiplos diálogos, conceitua patrimônio cultural como o conjunto de objetos de memória que definem nossa identidade

[...] tales como museos y sus colecciones, archivos, obras de arte, elementos o estructuras de carácter arqueológico, parques, edificios, materiales iconográficos, literarios, teatrales, cinematográficos y musicales, que tengan un valor excepcional desde el punto de vista histórico, estético, antropológico, etnológico, artístico y científico para la Humanidad. También sumamos a nuestra definición el acerbo de tradiciones, usos y costumbres, fiestas y formas de celebración que han configurado nuestra identidad y constituyen el patrimonio intangible. uitectónicas, plásticas, literarias, etc., elementos tangibles que podrán ser observados, usados, disfrutados, apreciados y valorizados por sucessivas generaciones. Se concreta también bajo formas intangibles, cuyos mecanismos de transmisión generacional - y "conservación" - son distintos, entre ellos el Patrimonio Digital (ABALLÍ, 2009, p.1).

Os estudos acerca de patrimônio e memória se inserem no campo da Ciência da Informação, visto que toda ação humana nos campos social, cultural e artístico (livros, artigos, banco de dados, arquivos, literatura, música, cinema, etc.), gera registro de informação e conhecimento. Segundo Araújo (2012, apud Bates, 1999), a Ciência da Informação estuda o mundo da informação registrada pela ação humana, sendo esta uma ciência interdisciplinar que utiliza abordagens de várias áreas a fim de compreender a questão informacional que por sua vez é múltipla, englobando a informação científica, tecnológica, gerencial, jornalística, genética, artística, bibliográfica, musical, etnográfica, arquivística, arquitetônica. Informação esta que está no cerne da cultura e, consequentemente, do patrimônio, geralmente organizadas em acervos e coleções a fim de garantir sua 
preservação e acesso.

Molina (2009), no prefácio do livro Ciência da Informação: múltiplos diálogos, destaca a Ciência da Informação como interdisciplinar e sua possibilidade de ser analisada sob diversas perspectivas, o que dificulta estabelecer seus limites enquanto disciplina científica, sendo a informação um recurso básico para todas as atividades humanas

Dado que la información es un recurso básico para todas las actividades humanas, laciencia de la información no se interesa sólo por las necesidades de información de la comunidad científica y técnica, sino de las de cualquier persona o institución, ya sea para la toma de decisiones, resolución de problemas o para actividades de ocio, diversión o entretenimiento. (MOLINA, 2009, p. ii).

O acesso à informação é fundamental ao exercício da cidadania, promovendo o desenvolvimento cultural e político, sendo relevante para o desenvolvimento humano, seja no campo científico, seja como necessidade em outros aspectos da vida humana (FREIRE, 2004). Muitas vezes o acesso depende de políticas públicas ou mesmo de leis, haja vista a Lei $\mathrm{n}^{\circ}$ 12.527/2011 que regulamenta o direito constitucional de acesso às informações públicas. Silva e Barros (2009) ressaltam que o desenvolvimento da área da informação é dependente de políticas públicas, sendo a informação estratégica, tanto em tempos de guerra, quanto em tempos de paz, e necessita ser tratada com atenção e competência para que cumpra seu papel se transformando em conhecimento através da qualidade do acesso.

Na prática, para que se transforme em conhecimento, a informação passa antes pelo acesso a ela, cujas possibilidades, obviamente, dependem das condições e da qualidade do acesso para que possam ocorrer a transferência e o aproveitamento da informação disponível. Nos tempos informacionais que vivemos na atualidade, conhecidos como da sociedade do conhecimento, novas abordagens na organização, no acesso e na transferência de informação precisam ser levados em conta pelos profissionais, que se vêem às voltas com uma miríade de novas tecnologias de informação e comunicação, de novas fontes, novos suportes, novas dimensões e novos planos, mesmo que, porventura, continuem dizendo respeito a texto, som e imagem. (SILVA; BARROS, 2009, p. viii)

A informação permeia toda a atividade humana e esta pluralidade de tipos de informação, por sua vez, pode se organizar em acervos e coleções com o propósito de serem registradas, organizadas, conservadas, pesquisadas e difundidas. Para cumprir essas tarefas, as instituições depositárias constroem suas políticas de acervo, que geralmente envolvem a produção de um Manual de Gerenciamento e Uso, "[...] fruto de um processo de trabalho intelectual coletivo e interdisciplinar, registra e sistematiza princípios, métodos e procedimentos técnicos e administrativos com vistas à preservação, à aquisição, ao empréstimo, ao descarte e à segurança das diversas tipologias de acervo" (FUNDAÇÃO JOAQUIM NABUCO, 2010).

Acervo e coleção são muitas vezes utilizados como sinônimos na linguagem coloquial, entretanto apresentam características específicas em determinados lugares de atuação, Ambos derivam do latim e de forma generalizada, definem reunião ou conjunto de coisas ou objetos. Utilizados nas áreas de museologia, biblioteconomia e arquivística. A palavra acervo também possui uma acepção jurídica - "acervo de herança" para designar uma massa hereditária. Uma curiosidade é que o termo acervo tem uso restrito a países ibero- 
americanos. Inglaterra e França utilizam o termo collection para designar tanto o primeiro como o segundo sentido.

No caso do Brasil e alguns outros países, vê-se uma relação hierárquica entre os dois termos, sendo acervo um conjunto não necessariamente ordenado de coisas. O Dicionário Aurélio traz a palavra amontoado para acervo; o Dicionário Michaelis, por exemplo, traz o sentido de "reunião confusa de objetos" e também “[...] conjunto de bens que constituem um patrimônio pessoal, institucional ou nacional”; enquanto coleção implica coesão entre os itens que a compõem. Segundo o Dicionário Aurélio é a "[...] reunião de objetos da mesma natureza". Para o Dicionário Michaelis é o "[...] conjunto de coisas da mesma natureza, reunidas para fins de estudos, comparação ou exposição, ou apenas pelo desejo e prazer de colecioná-las”. Na literatura de Ciência da Informação, utiliza-se Acervo para designar um conjunto geral, com corpo mais amplo, muitas vezes constituído de várias coleções. Já a Coleção refere-se, portanto, a um corpo coeso de itens que tem uma relação íntima entre si, como define a publicação Conceitos-chave de Museologia, é preciso que os itens reunidos em uma coleção "[...] formem um conjunto (relativamente) coerente e significativo".

Apesar dessa especificidade, as possibilidades de seleção, formato, tamanho e alcance das coleções são imensas. O historiador polonês Krzysztof Pomian (1934) menciona não ser possível estipular, por exemplo, a quantidade necessária de objetos para que um conjunto seja considerado como uma coleção, posto que isso depende de variáveis como local, as suas técnicas e o modo de vida, a capacidade de produzir e acumular e, principalmente, “[...] da importância que se atribui à comunicação entre o visível e o invisível por intermédio dos objetos etc." (POMIAN, 1984,p. 67).

As civilizações pré-clássicas e clássicas já reuniam coleções de símbolos de poder ou de determinada religião ou culto, onde os responsáveis elaboravam listas e formas de identificação desses objetos com o intuito de salvaguarda e de cuidar da informação relevante sobre os mesmos: quem os ofereceu, o que simbolizavam, a que culto respondiam, por que os tinham oferecido. Os primeiros gabinetes de curiosidades criaram formas de identificar e registar informação sobre os objetos que acumulavam com o objetivo de melhorar o ensino em disciplinas como a medicina e botânica, através de catálogos ilustrados. Da mesma maneira, nobres e reis também tinham suas coleções catalogadas, como símbolo de riqueza, prestígio e poder muitas vezes em forma de catálogos.

No fim do século XVIII, nasce da revolução francesa, instituições voltadas ao colecionismo e disseminação dos valores nacionais e, com elas, a necessidade de novas formas de catalogação. As coleções começaram a ser reunidas de forma pensada e estruturada, com objetivos específicos de ensino, de promoção social ou, simplesmente, estéticas. A prática de coletar, reunir e organizar está intimamente relacionada com a valorização da cultura humanista e o desenvolvimento da ciência, bem como relações de poder.

[...] as coleções, que, para os membros do meio intelectual e artístico, são instrumentos de trabalho e símbolos de pertença social, são, para os detentores do poder, insígnias da sua superioridade e também instrumentos que lhes permitem exercer uma dominação neste meio (POMIAN, 1984, p.79). 
Nesse cenário, surgem museus como o British Museum, o Louvre e o Museu do Vaticano com os primeiros catálogos de arte, arquitetura, filosofia, estética e ciência, e até mesmo tratando sobre a forma de se organizar coleções. A documentação e o inventário ganham importância na preservação do patrimônio com o aumento das coleções, porém os meios disponíveis limitavam as pesquisas e a difusão. As fichas e livros manuscritos eram geralmente cópias únicas, guardadas pelo responsável pela coleção e com acesso restrito, muitas vezes rasurados com atualizações de informações.

Com a revolução comunicacional e tecnológica, as mudanças foram velozes, passando para sistemas mais acessíveis, grande capacidade de processamento e, ao mesmo tempo, a sociedade "[...] alertada pelas consequências das guerras mundiais, tomou consciência da necessidade da salvaguarda do património através do seu registo e documentação" (MATOS, 2007 p.5). A sede de conhecimento da sociedade da informação, bem como o surgimento de museus públicos e privados, aumento das coleções, preocupação com salvaguarda, novos formatos de patrimônio, como mencionado anteriormente, são alguns dos motivos que levaram os museus e a museologia a buscarem novas formas de trabalho nos processo de gestão de suas coleções.

Desde o Iluminismo adquirimos o hábito de classificar, de separar conceitos na busca de uma objetividade científica (SILVA, 2002), o que originou a chamada sociedade da informação nas diferentes instituições que conhecemos como museus, bibliotecas e arquivos, cujos processos de institucionalização estão fundamentados nas práticas de inventariação, conservação e/ou exposição que foram sendo aprimoradas ao longo do tempo, embora essas instituições tenham se desenvolvido por caminhos diferentes ou mesmo independentes.

Arquivos, bibliotecas, museus, centros de memória, repositórios científicos, musicais, artísticos e outros, necessitam de um processo de tratamento, disponibilização e recuperação das informações neles contidas. Assim, recolher, tratar, transferir, difundir informações é objetivo comum das instituições de informação, preservação, cultura e memória, apesar da diversidade de origem dos acervos e diversas técnicas empregadas. Na introdução da obra Documentação Museológica e Gestão de Acervo, Volume 2 da Coleção de Estudos Museológicos produzido pela Fundação Catarinense de Cultura, Padilha (2014) explana:

É compromisso dos museus pensar a salvaguarda do seu acervo de modo a fazer com que a tríade pesquisa, comunicação e preservação seja realizada. Muitas são as ações que o profissional de museu desenvolve no que tange à gestão e ao controle do acervo: interpretar, organizar, documentar, recuperar e disponibilizar são etapas fundamentais para o tratamento da informação dos objetos museológicos e das práticas administrativas. (PADILHA, 2014, p.10)

Qualquer instituição que lide com acervos lida também com a gestão e controle do mesmo, bem como com sua preservação e pesquisa. Neste sentido, os vários manuais existentes, principalmente na área de museologia, oferecem uma base para que cada instituição, seja ela física ou virtual, museológica ou não, construa seu próprio método de gestão levando em consideração a tipologia de seu acervo (origem, formato e 
funcionalidade), sua vocação e seu público alvo. Apesar disso, o tema gestão é relativamente novo na museologia, sendo o primeiro seminário "Gestão Museológica: desafios e práticas, realizado em 2003 pela Pinacoteca do Estado de São Paulo, quando também foi oferecido um curso à distância de Gestão em Museus tendo como base o manual "Como gerir um museu", organizado por Patrick Boylan para o ICOM (CANDIDO, 2013)

Ainda hoje há na bibliografia apenas algumas tentativas de criar standards e com mais frequência manuais de boas práticas, mostrando dificuldade de se encontrar critério que seja padrão devido a enorme diversidade de instituições. Entretanto, internacionalmente vê-se uma bibliografia desenvolvida que tenta abarcar uma padronização de vocabulários e de campos para a inventariação, catalogação e gestão de acervos, através de pesquisas com colaboração de profissionais de diversos países nas instituições Collections Trust, no Reino Unido, em atividade há mais de quatro décadas, e do ICOM - International Council of Museums, principalmente através de seu comitê CIDOC - International Committee for Documentation. Há necessidade, no Brasil, de pesquisa sobre tipologia de acervos e tipos de gestão praticada nas instituições nacionais.

\section{GESTÃO}

A gestão de acervos e coleções, em sua maioria, estão previstas pelas instituições. Uma compreensão primária a partir da necessidade de produzir atividades sistêmicas que pretendem conduzir o melhor uso de documentos, informações através de um fluxo constante e ultra-dinâmico. Uma condição relevante a ser considerada são as vocações institucionais perante os documentos, arquivos, coleções e acervos. Trata-se de uma estrutura determinante para os objetivos da gestão destes elementos que constituem a materialidade da informação e da própria instituição. Portanto, a formação de acervos parte da construção de uma política de acervo, pela qual procedimentos teóricos, técnicos e gerenciais conduzem conjuntamente com a ideologia da instituição as bases para sua formação.

Temos como pressuposto que a política de acervos é parte de um processo ideológico e intelectual em sua formação (VERGUEIRO, 1989). Cristalizados, a instituição inicia diretrizes e sistematizações de seus documentos, arquivos, coleções e acervos. A gestão de acervos portanto, inicia-se numa condição do pensamento e reflexão vocacional em direção a uma materialidade de práticas e ações gerenciais.

Definido por alguns autores como um tripé conceitual (LADKIN, 2004; CYSNE, 2016), a formação de acervos se dará na condição sistemática de funções a cumprir da instituição a que pertence determinado acervo, através das diversas camadas da política institucional (acesso, difusão, proteção e etc), e suas regras de produção, desenvolvimento e manutenção de tal acervo.

Ressaltamos no início deste estudo que as condições de uma atualidade digital (condição digital), onde os processos de digitalização influem sobre as condições da humanidade com um todo (pessoas e instituições), em um idéia de um "mundo sistema" hiperconectado e ultra-dinâmico de fluxos informacionais, acabam por condicionar os sistemas informacionais, mesmo os dos acervos, a um critério de objetividade entre usuáriosinformação, usuários-coleções, usuários-acervos. Tal objetividade, enquanto processo de critério sistemático 
da construção de sistemas informacionais na construção de acervos irá incidir sobre a política de salvaguarda, propondo focalizações e segmentação técnicas e operacionais do funcionamento do acervo (COSTA, 2015).

É preciso separar metodologicamente no entanto, as diferenças entre a gestão de acervo e a gestão de coleções. Tendo como princípio que a primeira responde com especificidade à relação de usuários e sua pesquisa perante uma coleção, conforme suas necessidades informacionais. A segunda se refere às atividades gerenciais do próprio acervo a partir da coleta, interpretação e compreensão dos dados produzidos pelo ir e vir das coleções nos usos diversos das pesquisas e seus usuários.

Na gestão dos acervos e sua especificidade comentada acima referente aos seus usuários três aspectos terão uma inter-relação entre si. O primeiro deles será o planejamento da coleção que tenderá a determinar normativas (políticas) de aquisição, coletas e descartes. Um segundo aspecto produzirá uma espécie de inventário do acervo com base em seus atributos de qualidade, quantidade e cálculos de uso. Por fim o terceiro aspecto formativo do acervo irá produzir uma avaliação institucional do acervo com base uma métrica destinada a medir sua relevância e sua meta enquanto acervo (sua vocação) (COSTA, 2015).

O planejamento da coleção é uma atividade essencialmente primária na compreensão e formação de acervos. Necessariamente ou formalmente há uma conexão direta com os objetivos vocacionais da instituição que faz parte. Precisa em sua centralidade de planejamento conduzir institucionalmente uma visão de futuro para a informação e sua salvaguarda. Nasce deste lugar a formação política, conceitual e teórica do acervo; a política de acervo.

Fazem parte da política de acervos um universo de micropolíticas, altamente complementares como, orçamentária, comunicação, desenvolvimento (aquisição, manutenção, descarte) entre outras. Nota-se desde então que a formação de políticas para gestão de acervos é um processo contínuo, com envolvimento de toda a comunidade institucional a qual pertence, relacionando áreas e conhecimentos gerenciais que incidem verticalmente na condução das formações coleções e acervos com relevância operacional à instituição.

Se fazem necessárias que as políticas de acervo direcionem a produção de documentação, produzam pesquisas adequadas aos acervos, e permitam um controle integral de um manuseio com fins a produção de conhecimento e difusão de informação. Tendo em vista que todas estas condições são adaptáveis, verificamos o quão é extensa a gestão de acervos e coleções, e consequentemente de informação. Visualizamos que por mais difundidas e compartilhadas estejam, estas práticas e teorias normativas e gerenciais ainda sim, haverá uma multiplicidade de posições institucionais perante os acervos e seus usos, com condições próprias de operabilidade e ideologias.

Algumas relações elencadas como ideologias estão incutidas aos acervos que tendem a reproduzir comportamentos institucionais. Portanto fazem parte da formação de acervos, e como vimos, a partir de uma política bem definida, a determinação de normas, leis, previamente elencadas por uma conduta ética própria da instituição a que pertence. A conjunção das normativas, leis e um horizonte ético definido a partir das vocações institucionais, credibilizam o acervo junto ao seu público-usuário (PADILHA, 2014). Os acervos e 
coleções dependem de um conjunto bem formulado de política de acervo, programas de política de acervo (uma extensão a política enquanto processos), um horizonte ético e vocacional da instituição com vistas a ideia de futuro de sua capacidade de contribuição informacional e de conhecimento.

A exemplo, as ações a seguir conduzem a boas práticas como formular e aprovar aquisições e descartes com base decisões técnicas e contextuais sob critérios patrimoniais e culturais. Dar publicidade às ações internas e externas (quando aplicável) do acervo tende a produzir transparência das ações. A comunicação de descartes é usual em acervos públicos, mas também para públicos internos de usuários de instituições privadas com responsabilidade sobre seus processos frente aos seus usuários. A sistematização de documental do acervo, bem como detalhamento e indexações e taxonomias não só remetem a uma gestão de qualidade como produz novas dinâmicas de pesquisa e operabilidade das coleções e acervos. Os processos de adequação e equiparação a modelos já existentes por classe, categoria ou modelo de acervos conduz a aproximação com outros acervos permitindo integrações, compartilhamentos e potencializando usos conjuntos. A promoção de acessos e pesquisa constrói as relações de troca e pertencimento, materializando a referência do acervo e das coleções frente a comunidade. Portanto as decisões eficazes dependem especialmente de políticas eficazes. "[...] o documento mais importante do acervo do museu é a Política de Gestão do Acervo" (LADKIN, 2004).

Por fim, a gestão de acervos e coleções para existir e se realizar de forma eficaz, precisa de uma ação coordenada entre uma instância intelectual e teórica e outra instância gerencial de processos técnicos e processuais por meio de uma política de gestão construída a partir de uma diversidade de visões da instituição responsável que contribuam a uma visão de futuro quanto aos seus objetos produzidos e salvaguardados, que devem considerar sobretudo, a condição digital dos processos informacionais na contemporaneidade.

\section{PRÁTICAS}

Neste presente estudo sobre as práticas da gestão de acervos em suas mais diversas instâncias bibliográficas, arquitetônicas, biológicas e tantas outras - ficou constatado que existe certa transversalidade entre essas áreas. Essa observação nos fez perceber que a constituição de acervos e suas práticas de gestão estão cada vez mais imbricados e justapostos, endossando as tendências heterodoxas do capitalismo tardio de utilizar diferentes referenciais teóricos e empíricos dentro de um mesmo escopo.

Diversos espaços importantes de acervos brasileiros possuem essas características e especialistas de diferentes áreas têm destacado como temas variados que passam por questões como política, sociologia, cultura, turismo, arquitetura e patrimônio podem tangenciar essa temática simultaneamente e sem grandes obstáculos na construção dessa abordagem multidisciplinar.

Tomando como exemplo o Instituto Biológico de São Paulo que é inclusive um espaço tombado pelo Conselho de Defesa do Patrimônio Histórico, Arqueológico, Artístico e Turístico do Estado de São Paulo (CONDEPHAAT), vemos essa amplitude de um acervo diverso dentro de um espaço utilizado para os mais variados fins, tanto científicos ou mesmo recreativos como acontece com o Parque Ecológico "Monsenhor Emílio José Salim” abrigado dentro da área do IB. 
Outro exemplo que iremos explorar neste artigo é o acervo arquitetônico do bairro da Praia Grande em Manaus, explorado sob a ótica do Turismo Cultural proposta pelas pesquisadoras Karoliny Diniz Carvalho e Maria de Lourdes Netto Simões. No artigo "Reinterpretando o acervo arquitetônico do bairro da Praia Grande através dos lugares de memória" (2011), levantou-se alguns problemas relativos à exclusão da população oriunda deste local no processo de patrimonialização do bairro. Essa é uma questão importante e que é apontada pelas autoras para colocar em pauta processos inclusivos que possibilitem a participação popular na institucionalização dos acervos.

Abordando o desafio de falar sobre os tempos atuais, vamos considerar ainda um estudo de caso sobre o sistema Resource Description and Access (RDA) a fim de compreender a catalogação descritiva no século XXI e de que forma ela implica na gestão dos acervos e coleções no mundo contemporâneo. Como exemplo tomaremos a dissertação de mestrado defendida por Rosa Maria Rodrigues Corrêa (2008) a fim de termos um ponto de partida para nossas reflexões.

A diversidade do acervo digital em seus mais variados suportes (áudio, vídeo, texto etc.) e temáticas é outro ponto relevante dessa transversalidade que pode perpassar as práticas de gestão de acervos nos tempos atuais.

\section{O INSTITUTO BIOLÓGICO E SEU ACERVO DOCUMENTAL ${ }^{1}$}

O artigo homônimo escrito pelas profissionais do Instituto Biológico (IB): Márcia Maria Rebouças, Simone Bacilieri, Silvana D’Agostini, Nayte Vitiello, Luana Santamaría Basso, Érika Barbosa e Juliana Sganzerla Pereira, traça não só um percurso sobre a constituição do acervo documental do IB bem como dá pistas sobre a extensão e variedade dos diferentes itens que o constitui.

O texto começa apontando como se deu a inauguração do Instituto e sua relação direta com o combate à praga da broca do café que assolou os cafezais paulistas no final da década de 20 do século passado. Essa função social que o Instituto assumiu se refletiu em um trabalho científico e de pesquisa ostensivo de visitação às fazendas, desenvolvimento de produtos químicos, além de produções audiovisuais como o filme "História de um bichinho malvado" que "fazia lotar os trens" rumo ao IB com uma leva de trabalhadores rurais enviados pelos fazendeiros ávidos por entender como proteger seu patrimônio e acabar com a praga (REBOUÇAS et al, 2009, p. 96).

Obviamente, por sua aplicabilidade sócio-científica o Instituto ganhou importância política no Estado de São Paulo. O empreendimento realizado para solucionar a praga da broca do café gerou nada mais que 30 capítulos e 38 estampas produzidas pela comissão científica, chefiada pelo médico baiano Arthur Neiva. O então Instituto Biológico de Defesa Agrícola e Animal de São Paulo, nome original que o instituiu em 1927 pela Lei 2.243, passou a se chamar Instituto Biológico e de Defesa Agrícola, a quem é dada a direção da

\footnotetext{
${ }^{1}$ REBOUÇAS, Márcia Maria; BACILIERI, Simone; D’AGOSTINI, Silvana; VITIELLO, Nayte; BASSO, Luana Santamaria; BARBOSA, Érika; PEREIRA, Juliana S. Pereira. "O Instituto Biológico e seu Acervo Documental.” Cadernos de História da Ciência: Instituto Butantan. Vol. 1, Jan-Jul 2009.
} 
instituição a Arthur Neiva pelo então governador Júlio Prestes.

Com esse reconhecimento governamental, o IB amplia suas atividades para o cuidado aos animais e tratamento de doenças e desenvolvimento de soros e vacinas. Fazendeiros e trabalhadores do campo tinham acesso ao Instituto para consultarem seus animais e obter resposta sobre os males que poderiam estar afligindo essas crias. Isso abriu a oportunidade para o IB desenvolver pesquisas e registros diversos, ampliando ainda mais o acervo documental sobre doenças, processos de curas, remédios aplicados, procedimentos veterinários etc. Para além da questão puramente arquivística e bibliográfica, o Instituto passou ainda por muitas mudanças e ampliações diversas do seu acervo ao longo das décadas. Conforme apresentamos na introdução deste tópico sobre Práticas, a extensão de seu acervo perpassa também o museal, o arquitetônico e o paisagístico, indo além simplesmente da esfera documental. A presença do Parque Ecológico "Monsenhor Emílio José Salim" localizado em Campinas, mas que abriga parte do espaço constitutivo do Instituto sinaliza bem a extensão do seu acervo. Nele está situada a Fazenda Experimental Matto Dentro, hoje tombada, mas originalmente uma casa grande que abrigava uma senzala nos tempos coloniais e que foi uma das grandes produtoras de café no Estado. Diversos laboratórios que compõem o IB estão no entorno desse patrimônio histórico denotando o caráter diverso do espaço do Instituto.

Existe ainda um Centro de Memória localizado no Museu do Instituto Biológico que concentra os “[...] 180.000 documentos textuais de cientistas desde o início do século XX, 60.000 fotografias e 70.000 slides em vidro e 3.000 documentos sobre arquitetura" que são o foco do percurso traçado pelas autoras nesse artigo (REBOUÇAS et al., 2009, p. 95).

Tendo em vista que este é apenas um breve comentário sobre o trabalho desenvolvido nesse estudo sobre o IB, intentamos destacar a transversalidade dos acervos que o compõem e como eles estão intrinsicamente ligados ao desenvolvimento do Instituto ao longo de sua história e atuação política. A seguir, abordaremos o caso do acervo arquitetônico do bairro Praia Grande em Manaus, que oferece um outro viés, também complexo, para essa discussão.

\section{REINTERPRETANDO O ACERVO ARQUITETÔNICO DO BAIRRO DA PRAIA GRANDE ATRAVÉS DOS LUGARES DE MEMÓRIA²}

O artigo homônimo a este subtópico trata de questões como patrimônio cultural, espaço urbano e turismo, no acervo arquitetônico do bairro da Praia Grande em Manaus. Analisando os espaços que compõem a memória afetiva e sentimento de pertença dos habitantes daquela região, as autoras procuram discutir de que forma esses locais tombados realmente representam o que as pessoas que ocupam e transitam diariamente por esses logradouros entendem como símbolos de sua história.

Nesse âmbito entram questões como a gentrificação e a "cenarização" dos espaços públicos para fins

\footnotetext{
${ }^{2}$ CARVALHO, Karoliny Diniz; \& SIMÕES, Maria de Lourdes Netto. Reinterpretando o acervo arquitetônico do bairro da Praia Grande através dos lugares de memória. PASOS: Revista de Turismo y Patrimonio Cultural. Volume 9, n. 4, p. 633-646, 2011.
} 
econômicos sem incluir as práticas culturais e sociais dos moradores nesse processo. As autoras propõem como alternativa a esse modelo de patrimonialização, que exclui o habitante, uma prática conhecida como Turismo Cultural. Essa forma de turismo que "baseia-se na produção cultural e espiritual de uma comunidade" e que possibilita “[...] uma maior aproximação entre visitantes e anfitriões" procura minimizar a lacuna existente entre o que o poder público elege como memória e o que o povo que vive nesses espaços entende como parte de sua história, algo que nem sempre está alinhado nas políticas de patrimonialização.

Um exemplo fatídico citado no artigo é o Tambor de Crioula, prática cultural maranhense tida por seus brincantes como símbolo de uma história viva que ainda se faz presente. As autoras descrevem essa tradição como forma de "[...] resistência e liberdade dos negros" (CARVALHO. SIMÕES, p. 641, 2011) que manifestam uma de suas maiores expressões culturais no espaço público do bairro da Praia Grande. Locais como a Rua Portugal e a Feira da Praia Grande são tidos em alta conta pelos praticantes justamente por serem os logradouros de suas performances e espaço de convívio entre os seus brincantes. Tendo em vista que o espaço público é muito mais que um mero local de passagem e sim um terreno de disputas simbólicas, políticas e econômicas que vão desde a especulação imobiliária até a gentrificação — duas pontas de uma mesma questão - é importante entender o que está em jogo quando os habitantes ocupam esses locais e quando o poder público elege um determinado logradouro como patrimônio.

Um contraponto colocado no artigo é justamente o fato de que o Convento das Mercês, fundado em 1654 pelos padres Mercedárius e que ao longo do século XIX foi transformado em base militar para sede dos bombeiros e quartel da polícia, revela a desconexão entre a memória afetiva popular e os locais que hoje possuem função museal, como é o caso do Convento que abriga ainda a Fundação da Memória Republicana. As autoras pontuam que (CARVALHO; SIMÕES, 2011):

Os entrevistados que indicaram o Convento das Mercês como local de significância histórica e cultural fizeram-no por relacioná-lo restritamente às apresentações de grupos de cultura popular, tais como de bumba-meu-boi que ocorrem nesse espaço durante o mês de junho. A sua função, enquanto prédio de manifestação da fé católica, não se reatualizou na fala dos moradores entrevistados. O patrimônio arquitetônico não foi lembrado, nem a sua função atual de abrigar mostras e exposições de caráter cultural.

Ainda sobre essa fé católica elas destacam que outros espaços como a Igreja do Desterro constituem um espaço de memória e afeto muito mais significativos para a população daquela região, o qual elas descrevem como "patrimônio espiritual". É importante refletir sobre a forma como acesso e o uso que é dado ao acervo do bairro da Praia Grande em Manaus a fim de equilibrar o interesse dos "anfitriões" com os dos "visitantes", como bem colocaram as autoras.

Afinal, o que realmente representa a memória da cidade? Sua "cenarização" para fins econômicos ou as práticas culturais que ali tecem uma narrativa de "resistência e liberdade"? É possível desenvolver o turismo e a cidade sem excluir os mais pobres desse processo? O que é desenvolvimento? Como tem se dado os processos de patrimonialização e gestão de acervos arquitetônicos no Brasil? Será que o Turismo Cultural é 
capaz de resolver essa fricção entre mercado, governo e interesses populares? Essas são algumas das perguntas que o artigo de Karoliny Diniz Carvalho e Maria de Lourdes Netto Simões suscitam no leitor e que consideramos como válidas para se pensar as práticas sobre gestão de acervos no Brasil.

\section{CATALOGAÇÃO DESCRITIVA NO SÉCULO XXI: UM ESTUDO SOBRE O RDA ${ }^{3}$}

A dissertação de mestrado homônima a este subtópico defendida pela pesquisadora Rosa Maria Rodrigues Corrêa no Programa de Pós-Graduação em Ciência da Informação, da Faculdade de Filosofia e Ciências, da Universidade Estadual Paulista (UNESP) traz um panorama sobre o estado da arte do sistema de catalogação Resource Description and Access (RDA) e as soluções e alternativas que pode oferecer ante os desafios da catalogação descritiva no século XXI.

Em termos da transversalidade, presente nesse tipo de acervo, fica claro que um dos principais desafios a um sistema de catalogação que lida com o campo digital está justamente na variedade de linguagens e suportes que fazem parte desse meio. A ampla recuperação, acesso e uso de imagens, vídeos, textos e demais formatos que compõem a virtualidade evidencia a complexidade desse âmbito.

Além disso, o acesso a um mesmo acervo em diferentes pontos do globo e o diversos usos que podem ser dado a eles também constituem um problema no que diz respeito à universalização dos procedimentos de catalogação em um ambiente como o atual. Adiciona-se ainda como entrave as limitações econômicas e estruturais de alguns países ou locais específicos que podem comprometer a gestão correta dos acervos disponíveis e a aplicação assertiva do sistema RDA em sua manutenção.

O ritmo acelerado da internet e a produção ininterrupta de novos itens colecionáveis e passíveis de se tornarem acervos também apresenta outro obstáculo ao caminhar mais lento das pesquisas científicas e desenvolvimento de novas plataformas que possam contribuir para esse processo.

No Brasil, já existem esforços nesse sentido como os sistemas PERGAMUM, ALEPH e VIRTUA citados pela própria autora (p. 31-32, 2008). Porém, nem todas as bibliotecas estão amplamente equipadas para tirar máximo proveito desses recursos ou mesmo de alternativas computacionais mais simples que poderiam impulsionar o acesso digital no país a acervos diversos como acontece nos chamados "países desenvolvidos", conforme Corrêa aponta.

A necessidade de se avançar sem apagar o passado, ou seja, conservar aspectos de sistemas anteriores de catalogação para que haja um progresso real do campo é uma questão importante que esse estudo de caso revela. Para haver uma gestão assertiva é necessário que a atualização não suprima os dados prévios, nem desperdice oconhecimento acumulado por bases anteriores. Isso nos faz refletir sobre acervos que são geridos de forma irregular, sem o devido controle e correta continuidade do trabalho realizado até então. Situações como essa dificultam a recuperação comprometendo os processos subsequentes de gestão da informação.

Apesar de tantos desafios, Corrêa aponta que o RDA se coloca como um dos melhores modelos a serem utilizados devido aos aprimoramentos baseados em sistemas anteriores, sobretudo os modelos conceituais desenvolvidos pela International Federation of Libraries Association (IFLA). Todavia, a autora 
afirma que o RDA ainda erra por não possuir um guia definitivo que possa universalizar sua aplicação por parte dos catalogadores. A pesquisa dela nos sugere de que é preciso desenvolver sistemas de catalogação passíveis de contextualização mas que não abram espaço para a falta de critérios em sua utilização. Por mais que o RDA possua avanços ainda não se constitui como sistema perfeito e nem poderia. Todas essas nuances apresentadas pela autora são relevantes quando o assunto são práticas de gestão de acervos e a melhor maneira de operacionalizá-las.

\section{CONSIDERAÇÕES}

A gestão de coleções e acervos analisados neste estudo perante uma realidade contemporânea de suas constituições e seus usos produzem uma grande variedade de percepções. Primeiramente é notório que em um mundo em vias de digitalização dos processos da vida, existem diversos tipos de fluxos de dados com uma produção ininterrupta de documentos que produzem uma infinidade de fundos documentais generalizantes. Ao mesmo tempo que o ocorre o crescimento exponencial de documentos, é proporcional o número de instituições. Há uma possível relação direta entre estas quantizações e consequentemente a produção de acervos por parte de várias destas instituições.

Não é possível apontar normativas globalizantes, unificadoras ou unânimes. Cada entidade possui uma cultura institucional que por sua vez, possui vocações próprias perante a seus objetivos internos e seus objetivos na sociedade, o que conduz a produção de diferentes abordagens sobre o que produzem, como produzem, para quem produzem, e neste sentido, a sua contribuição com a produção de documentos, coleções, acervos, informação e conhecimento.

Percebe-se no entanto, que é compartilhado, e transferido de outras experiências a gestão destes acervos e coleções em alguns critérios de similaridade da construção das ações gerenciais, principalmente a respeito das bases da construção documental de um norma que se inicia no ponto intelectual e teórico das instituições, para promover a edificação de uma política de gestão de acervos própria com ações prática, mas sem evidentemente desconsiderar as experiências correlatas de outros campos e áreas.

E notório um escaldamento de técnicas e ações efetivamente práticas de um modelo de acervo ou coleção, para outros. Porém a formação da política de gestão, sua condução de horizonte ético, cultural, vocacional e seus programas de política de gestão como extensão dos processos da gestão no núcleo e no entorno dos acervos são peculiares e singulares a cada instituição.

Outra condição inerente a todos os acervos na contemporaneidade relaciona-se com a condição de operar ou a digitalização de suas bases, ou de inserir pouco a pouco processos digitais de informação de seu acervo, bem como sua operações técnicas, os acolhimentos e os recolhimentos do comportamento de seus verdadeiros usos e usuários.

Ainda que particularizados em suas singularidades, os acervos e coleções neste universo "total-digital" tendem a interpolar-se diante da potencialidade de conversões, integrações, complementações.

Esse cenário aponta ainda desafios no que diz respeito à recuperação, acesso e uso de todos esses itens 
sejam materiais ou imateriais passíveis de serem colecionados e tornados acervos. Não só a produção de tudo isso tem se dado a um ritmo veloz como a variação do comportamento do público que é cada vez mais amplo e diverso e que pode migrar de um campo de interesse para outro sem grandes hesitações.

Nesse sentido, desenvolver sistemas e formas de gestão que dêem conta dos desafios atuais exige um conhecimento técnico-científico e espírito crítico que nem sempre consegue acompanhar o frenesi dos tempos atuais. A tentação em dar respostas rápidas a isso pode também comprometer a qualidade dos serviços prestados e formas de gestão feitas até então.

Portanto, desde as principais políticas de aquisições e descartes, fundamentais a gestão dos acervos e coleções para a sua manutenção e desenvolvimento, os processos de permuta, empréstimos, transferências, bem como, as doações, trocas, repatriações tendem a ganhar ou produzir novos sentidos e novos formatos por meio da gestão da informação destes acervos diante das novas tecnologias. Inclusive temos em questão na atualidade o sentido de descarte a partir de uma perspectiva de um "não-descarte total" como um sentido de perda plena, mas de um reaproveitamento possível?

O que consideramos pertinente neste estudo é a compreensão de que na contemporaneidade a produção e gestão de acervos e coleções ganha novos contornos e potencialidades. Ampliando fronteiras definidas pela fisicalidade para fronteiras de materialidade informacional para a constituição das sociedades, perante uma ideia central de patrimônio que depende exclusivamente da diversidade de políticas de acervo possíveis às instituições, mediante critérios norteadores, culturais e vocacionais, detentoras de um processo informacional potencial de uma sociedade. Tal processo agora parece ser mais compartilhado de responsabilidades entres o agentes que até então conhecíamos por sua centralidade social (Museus, Acervos Públicos) e que na atualidade parecem estar em vias de mudança.

\section{REFERÊNCIAS}

ABALLÍ, Isidoro Fernández. La información como patrimônio. In: SILVA, Helen de Castro, BARROS, Maria Helena T. C. de (org.). Ciência da Informação: múltiplos diálogos. Marília: Oficina Universitária Unesp, 2009. p. 1-21.

ARAÚJO, Ana Cláudia Henriques. Informação escondida: o processo de gestão de acervos artísticos em instituições financeiras brasileira. In: COLETIVO DA PÓS-GRADUAÇÃ̃ EM ARTE: ENTRE LINHAS, 3; Brasília. Anais... Brasília: UNB, 2014.

BURCAW, G. E. Introduction to Museum Work. 3ed. Walnut Creek: Altamira Press, 1997.

BITTENCOURT, José N. Desconstruindo e reconstruindo acervos de documentos no Museu Histórico Nacional. In: SEMINÁRIOS DE CAPACITAÇÃO MUSEOLÓGICA, 2004, Belo Horizonte. Anais...Belo Horizonte: Instituto Cultural Flávio Gutierrez, 2004. p. 133-143.

CARVALHO, Karoliny Diniz; SIMÕES, Maria de Lourdes Netto. Reinterpretando o acervo arquitetônico do bairro da Praia Grande através dos lugares de memória. PASOS: Revista de Turismo y Patrimonio

Cultural. Cidade do México, México. v 9, p. 633-646, 2011. 
CANDIDO, Manuelina Maria Duarte. Gestão de museus, um desafio contemporâneo: diagnóstico museológico e planejamento. Porto Alegre: Medianiz, 2013.

CORRÊA, Rosa Maria Rodrigues. Catalogação descritiva no século XXI: Um estudo sobre o RDA. 2008. 75p. Dissertação (Mestrado em Ciência da Informação) - Faculdade de Filosofia e Ciências Humanas, Universidade Estadual Paulista, Marília, 2008.

COSTA, Maria de Fátima Oliveira; CYSNE, Fátima Portela; SILVA, Adriana Nóbrega. Política de desenvolvimento e gestão do acervo da bilblioteca universitária: estudo de caso na biblioteca da UNILAB. In: ENCONTRO NACIONAL DE PESQUISA EM CIÊNCIA DA INFORMAÇÃO, 17; Salvador, 2016. Anais... Salvador: UFBA, 2016. p. 2134-2149.

COSTA, Maria de Fátima Oliveira; CYSNE, Maria do Rosário de F. P.; SILVA, Adriana Nóbrega da; GUERRA, Maria Áurea Montenegro. O usuário frente a arquitetura da informação no sistema de busca. In: Maria Antonia Garcia Moreno, Paula Alexandre Ochoa de Carvalho Telo. (Org.). In: DESAFIOS Y OPORTUNIDADES DE LAS CIENCIAS DE LA INFORMACION Y DOCUMENTACION EN LA ERA DIGITAL, 7; Madrid, 2015. Actas del Encuentro Ibérico EDICIC, 2015. Universidad de Madrid: Universidade Nova de Lisboa, 2015, p. 1-19

DESVALLÉES, A., \& MAIRESSE, F. (2014). Conceitos-chave de museologia. São Paulo: Comitê Brasileiro do Conselho Internacional de Museus: Pinacoteca do Estado de São Paulo, Secretaria de Estado da Cultura, 2013.

DICIONÁRIO Aurélio On-line. Disponível em: https://dicionariodoaurelio.com. Acesso em: junho 2018.

DICIONÁRIO Michaelis On-line. Disponível em: http://michaelis.uol.com.br/. Acesso em junho de 2018

FUnDAÇÃo JOAQUim NABUCO. Política de Acervo: Manual de Gerenciamento e Uso. Recife: Fundação Joaquim Nabuco, 2010.

LADKIN, Nicola. Gestão do Acervo. In: Boylan, Patrick J. Como Gerir um Museu: manual prático. São Paulo: Secretaria de Cultura do Estado de São Paulo, p. 14-24, 2015.

MATOS, Alexandre Manuel Ribeiro. Os sistemas de informação na gestão de colecções museológicas: contribuições para a certificação de museus. 2007. Dissertação (Mestrado em Museologia) - Faculdade de Letras, Universidade do Porto, Porto, 2007.

REBOUÇAS, Márcia Maria; BACILIERI, Simone; D’AGOSTINI, Silvana; VITIELLO, Nayte; BASSO, Luana Santamaria; BARBOSA, Érika; PEREIRA, Juliana S. O Instituto Biológico e seu Acervo

Documental. Cadernos de História da Ciência: Instituto Butantan. v. 5, n.1, p. 95-122, Jan-Jul 2009.

PADILHA, Renata Cardozo. Documentação Museológica e Gestão de Acervo. Florianópolis: FCC, 2014.71 p. (Coleção Estudos Museológicos, v.2)

POMIAN, Krzysztof. Colecção. In: ENCICLOPÉDIA Einaudi. 1 - Memória-História. Porto: Imprensa Oficial - Casa da Moeda, 1984. p. 51-86.

REAU, L. L'organisation des musées. In: Revue de Synthèse Historique, t. 17, p.146-170 e 273-291, Paris 1908.

SILVA, Helen de Castro, BARROS, Maria Helena T. C. de (org.). Ciência da Informação: múltiplos diálogos. Marília: Oficina Universitária Unesp, 2009. 114 p. 
THE COUNCIL FOR MUSEUMS, ARCHIVES AND LIBRARIES. Benchmarks In Collection Care for Museums, Archives and Libraries: a self-assessment checklist. London: Resource, 2002.

VERGUEIRO, Waldomiro. Desenvolvimento de Coleções. São Paulo: Polis / APB, 1989. 